\section{Commentary: Targeting the Achilles' heel of the Ross procedure}

\author{
James A. Brown, MA, ${ }^{\mathrm{a}}$ and Ibrahim Sultan, $\mathrm{MD}^{\mathrm{a}, \mathrm{b}}$
}

First described in 1967 by Donald Ross, replacement of the aortic valve by pulmonary autograft implantation has provided an alternative to bioprosthetic and mechanical valves in the aortic position. ${ }^{1}$ With more than 50 years of experience, some long-term data support the superiority of the pulmonary autograft in younger patients, given its increased durability, superior hemodynamics, and improved survival, compared with mechanical and bioprosthetic valves. Despite these data, the Ross procedure has had limited use because of the technical complexity of the operation, which has only increased over time. For instance, whereas Donald Ross originally described a subcoronary technique, full root replacement techniques have been progressively more utilized to improve long-term outcomes. However, another major limiting factor for the widespread use of the Ross procedure is concern over the potential failure of 2 valves, especially long-term dysfunction of the pulmonary homograft.

In an elegant and highly detailed study, Chauvette and colleagues $^{2}$ have significantly contributed to our understanding of pulmonary homograft dysfunction after the Ross procedure. With hope of reducing the incidence of homograft dysfunction, there has been an increase in utilization of decellularized grafts to limit progressive postoperative inflammation and subsequent stenosis development; however, there is a paucity of data to support this idea.

\footnotetext{
From the a Division of Cardiac Surgery, Department of Cardiothoracic Surgery, University of Pittsburgh; and ${ }^{\mathrm{b}} \mathrm{Heart}$ and Vascular Institute, University of Pittsburgh Medical Center, Pittsburgh, Pa.

Disclosures: The authors reported no conflicts of interest.

The Journal policy requires editors and reviewers to disclose conflicts of interest and to decline handling or reviewing manuscripts for which they may have a conflict of interest. The editors and reviewers of this article have no conflicts of interest.

Received for publication June 21, 2020; revisions received June 21, 2020; accepted for publication June 23, 2020; available ahead of print July 12, 2020.

Address for reprints: Ibrahim Sultan, MD, Division of Cardiac Surgery, Department of Cardiothoracic Surgery, University of Pittsburgh Medical Center, 5200 Centre Ave, Suite 715, Pittsburgh, PA 15232 (E-mail: sultani@upmc.edu).

J Thorac Cardiovasc Surg 2022;163:1306-7

$0022-5223 / \$ 36.00$

Copyright (c) 2020 by The American Association for Thoracic Surgery

https://doi.org/10.1016/j.jtcvs.2020.06.097
}

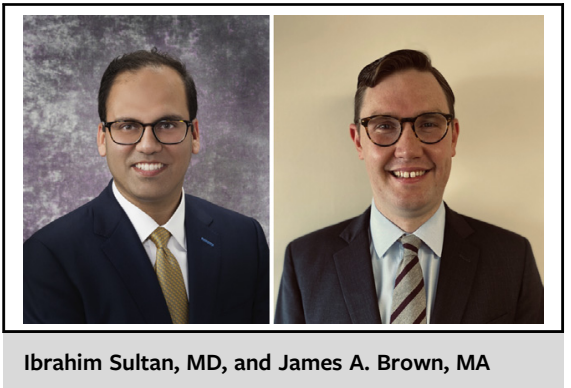

CENTRAL MESSAGE

The incidence of homograft

dysfunction and reintervention

may be low with the use of de-

cellularized pulmonary homo-

grafts because they may limit

progressive inflammation and

subsequent stenosis.

The Canadian Ross Registry is a paradigm of data-driven innovation that has improved patient outcomes, and the authors should be applauded for their excellent results. In an observational study of 466 consecutive patients who underwent a Ross procedure utilizing a decellularized homograft, they sought to assess the incidence, predictors, and morphology of pulmonary homograft dysfunction. Their primary outcome was homograft dysfunction, defined as peak pulmonary gradient $>30$, pulmonary regurgitation $>2+$, or any reintervention on the pulmonary homograft. Prudently, given the shorter follow-up of their cohort, they used a low peak pulmonary gradient to improve their sensitivity for detecting dysfunction; however, direct assessment of right ventricular function is arguably more sensitive for predicting dysfunction. Principally, they found that the incidence of homograft dysfunction and subsequent reintervention are acceptably low with the use of decellularized grafts. Moreover, they confirmed a well-known association of young age with dysfunction, which was notably the only significant predictor of dysfunction for the decellularized cohort. They found that the instantaneous risk of developing homograft dysfunction is biphasic, with its highest rate during the first year after surgery. Moreover, from granular echocardiographic data, they identified a subgroup of patients who had steady, progressive increase of their peak pulmonary gradient during the first postoperative year, which suggests the importance of 
closely monitoring this variable during the first postoperative year.

An important implication of this study suggests that inflammation is an important mediator of homograft stenosis and dysfunction. The authors defend this view on the grounds that stenosis happens at all levels of the graft, including the proximal suture line, mid conduit, and distal suture line, with nearly $60 \%$ of their stenoses occurring midway along the conduit. In conjunction with the finding that all peak pulmonary gradients upon leaving the operating room were $<10$, these morphologic patterns of stenosis suggest that dysfunction is unlikely to be related to surgical technique. Based on data from their series, they suggest that the decellularized homograft may perform better in the long run than the standard homograft because it may be less proinflammatory. Although the low rate of homograft dysfunction in their series is impressive and despite the fact that we routinely utilize a decellularized homograft for pulmonary valve pathology, it may be early to say that decellularized homografts ought to become the standard homograft. These data do not yet constitute long-term results because the median follow-up was only 2.2 years, and the type of homograft employed was not significantly associated with the cumulative incidence of homograft dysfunction in their study. Despite these limitations, this study provides invaluable, granular data that improves our understanding of homograft dysfunction, and may lead to an incremental reduction in homograft dysfunction after the Ross procedure, which continues to be the Achilles' heel of this operation.

\section{References}

1. Ross DN. Replacement of aortic and mitral valves with a pulmonary autograft Lancet. 1967;2:956-8.

2. Chauvette V, Bouhout I, Tarabzoni M, Pham M, Wong D, Whitlock R, et al Pulmonary homograft dysfunction after the Ross procedure using decellularized homografts - a multicenter study. J Thorac Cardiovasc Surg. 2022;163:1296-305.e3.
See Article page 1296.

\section{Commentary: I want to believe it... so it must be true}

\author{
Edward L. Bove, MD
}

Chauvette and colleagues ${ }^{1}$ present a retrospective review of a large cohort of patients undergoing the Ross procedure using data collected from the Canadian Ross Registry. An important objective was to evaluate the outcomes of decellularized pulmonary homografts used to reconstruct the right ventricular outflow tract. Patients were reviewed with the aim to assess the incidence, predictors, progression, and morphology of homograft dysfunction. The

\footnotetext{
From the Department of Cardiac Surgery, The University of Michigan Medical School, Ann Arbor, Mich.

Disclosures: The author reported no conflicts of interest.

The Journal policy requires editors and reviewers to disclose conflicts of interest and to decline handling or reviewing manuscripts for which they may have a conflict of interest. The editors and reviewers of this article have no conflicts of interest.

Received for publication July 1, 2020; revisions received July 1, 2020; accepted for publication July 1, 2020; available ahead of print July 11, 2020.

Address for reprints: Edward L. Bove, MD, Department of Cardiac Surgery, University of Michigan Medical School, 5144 Cardiovascular Center, 1500 E Medical Center Dr, Ann Arbor, MI 48109 (E-mail: elbove@umich.edu).

J Thorac Cardiovasc Surg 2022;163:1307-8

$0022-5223 / \$ 36.00$

Copyright (C) 2020 by The American Association for Thoracic Surgery

https://doi.org/10.1016/j.jtcvs.2020.07.016
}

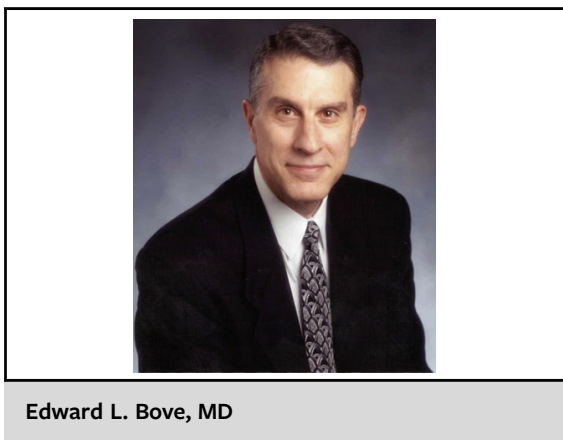

CENTRAL MESSAGE

Decellularized homografts have greater durability than standard grafts. This is a finding that many, if not all of us, can easily get behind. But do the methods used in this study justify the conclusions?

data set included nearly 500 patients, with a mean follow-up of just more than 2 years. Homograft dysfunction was defined as a peak gradient $>30 \mathrm{~mm} \mathrm{Hg}$, pulmonary valve regurgitation $>2+$, or the need for homograft reintervention. Thirty patients $(6 \%)$ met at least 1 criterion for 